\title{
PENGARUH MEDIA PEMBELAJARAN JENDELA ILMU TERHADAP HASIL BELAJAR IPS SISWA KELAS V DI SDN TENGGILIS MEJOYO 1 SURABAYA
}

\author{
Ellen Wanodya Ghati \\ STKIP PGRI Bangkalan \\ Email : ellen.wanodyaghati@gmail.com
}

\begin{abstract}
Learning success are based on many factors, one of them is teacher, who designing the learning process. The teacher has an opportunity to choose the Learning models, methods, techniques, tactics, strategies, and learning media. Learning media is one of the important aspects that able to affect learning process. It can help teacher and student in learning process, so that, it will determine the result if teacher could choose the media that suitable for the lesson. This article explain about the effect of Jendela ilmu Learning media to social science learning in the fifth grade. This researchment was using two classes, one for control, and one for experiment class. It took place in the fifth grade of Tenggilis Mejoyo 1 Surabaya students. The researchment was began by divided the class into some groups, explained the material, did in the teamwork and then did the Result test. The data was collected from from result test. And it analyzed with t-test. The researchment result showed the using of Jendela Ilmu, able to increase the study result. So that, there is an influence of using Jendela Ilmu learning media in Social Science Learning in fifth grade.
\end{abstract}

Kata Kunci : Media Pembelajaran Jendela Ilmu, IPS, hasil Belajar

\begin{abstract}
Abstrak
Keberhasilan pembelajaran didasarkan kepada banyak faktor, salah satunya adalah guru yang merancang pembelajaran. Guru memiliki tanggung jawab untuk memilih model pembelajaran, metode, tehnik, taktik, strategi serta media pembelajaran. Media pembelajaran merupakan salah satu aspek yang penting dimana media pembelajaran dapat memengaruhi proses pembelajaran. Media pembelajaran dapat membantu guru dan siswa di dalam proses pembelajaran sehingga penting kiranya untuk memilih media pembelajaran yang sesuai. Artikel ini menjelaskan tentang efek salah satu media pembelajaran, yaitu media pembelajaran jendela ilmu yang digunakan dalam pembelajaran Ilmu Pengetahuan Sosial (IPS) kelas lima Sekolah Dasar (SD). Penelitian ini menggunakan dua kelas, kelas kontrol dan kelas eksperimen, dimana kedua penelitian tersebut dilakukan di kelas lima di SD Tenggilis Mejoyo 1 Surabaya. Penelitian diawali dengan membagi kelas menjadi beberapa kelompok, menjelaskan petunjuk-petunjuk yang harus dilakukan, berdiskusi sebelum dilakukan evaluasi. Data diperoleh dari hasil belajar siswa yang kemudian dianalisis dengan menggunakan uji-t. Hasil menunjukkan jika penggunaan jendela ilmu dapat meningkatkan hasil belajar siswa.
\end{abstract}

Keywords : Jendela Ilmu Learning Media, Social Science, Learning Result. 
PENDAHULUAN

Pendidikan merupakan salah satu kebutuhan masyarakat. Pendidikan adalah usaha sadar dan terencana untuk mewujudkan suasana belajar dan proses pembelajaran agar peserta didik secara aktif mengembangkan potensi dirinya untuk memiliki kekuatan spiritual keagamaan, pengendalian diri, kepribadian, kecerdasan, akhlak mulia, serta keterampilan yang diperlukan dirinya dan masyarakat. di Indonesia, jenis pendidikan di bagi menjadi tiga berdasarkan formalitasnya, yaitu pendidikan Formal, Non formal dan Informal.

Pendidikan formal adalah $\mathrm{k}$ egiatan yang sistematis, berting kat/berjenjang, dimulai dari sekolah dasar sampai dengan perguruan tinggi dan yang setaraf dengannya; termasuk kedalamnya ialah kegiatan studi yang berorientasi akademis dan umum, program spesialisasi, dan latihan professional, yang dilaksanakan dalam waktu yang terus menerus. Pendidikan formal ini juga telah tertulis pada Peraturan pemerintah Nomor 47 tahun 2008. Dimana setiap warga negara memiliki hak untuk mengenyam pendidikan.

Pendidikan formal memiliki beberapa jenjang pendidikan. Diantaranya adalah Sekolah Dasar (SD), Sekolah Menengah Pertama (SMP), Sekolah Menengah Atas (SMA). Dimana masing-masing peserta didiknya memiliki ciri khas dan karakteristik yang berbeda, berdasarkan tugas perkembangan yang harus dicapainya. Baik kemampuan kognitif, afektif maupun psikomotornya.
Pencapaian tugas perkembangan di Sekolah Dasar akan mempengaruhi perkembangan di jenjang berikutnya, sehingga inilah mengapa diperlukan proses pembelajaran yang sesuai sehingga mendapatkan hasil yang optimal.

Hal itu pulalah yang juga mempengaruhi guru dalam menentukan model, metode, pendekatan, strategi, teknik, dan taktik pembelajaran serta media yang akan digunakan guna mencapai tujuan pembelajaran yang sudah ditentukan.

Penggunaan

media pembelajaran di dalam suatu proses belajar mengajar sangatlah dibutuhkan. Karena media pembelajaran dapat digunakan sebagai alat bantu guru dalam menjelaskan pelajaran atau materi yang dibahas kepada siswa. Pemilihan media yang tepat, dapat membuat siswa lebih inovatif, Kreatif, dan Aktif di dalam pembelajaran. Sehingga pembelajaran akan menjadi menarik dan menyenangkan.

Berdasarkan fakta yang ada di lapangan, hafalan merupakan salah satu cara konvensional yang selalu dilakukan pada hampir semua mata pelajaran. mata pelajaran Ilmu pengetahuan Sosial (IPS) khususnya, Hal ini tentunya perlu dirubah. Apabila hal ini terus diterapkan, maka akan memunculkan kebosanan pada siswa. Rasa bosan inilah yang dapat berpengaruh pada berkurangnya minat belajar siswa dan pada berpengaruh besar pada hasil prestasi belajar siswa.

Maka, berdasarkan dari uraian di atas, maka penulis tertarik untuk mengulas tentang salah satu 
media pembelajaran yang dapat digunakan dalam mata pelajaran IPS. Ulasan ini tentunya didassarkan pada penelitian yang telah dilakukan sebelumnya oleh penulis, yaitu "Penggunaan Media Pembelajaran "Jendela Ilmu" Terhadap Hasil Belajar IPS siswa kelas V SD"

\section{METODE PENELITIAN}

Metode penelitian yang akan menenetukan hasil dari sebuah penelitian. Di dalam penelitian ini, karena itulah metode penelitian sangatlah penting di dalam sebuah penelitian. Metode penelitian juga berfungsi sebagai pertanggung jawaban terhadap hasil penelitian. Menurut Sugiyono (2008:108) bentuk-bentuk desain eksperimen terbagi atas beberapa bentuk, yaitu: Pre-Eksperimental Design, True Experimental Design, Factoral Design, dan Quasi Eksperimental Design.

Dalam penelitian ini yang bertindak sebagai peneliti adalah guru sendiri. Rancangan penulisan ini menggunakan True Experimental Design dalam bentuk Posttest-Only Control Design. Di dalam desain ini, terdapat dua kelompok yang masing-masing dipilih secara random (R). Kelompok pertama diberikan perlakuan yaitu dengan menggunakan media pembelajaran Jendela Ilmu $(\mathrm{X})$ dan kelompok yang lain tidak diberikan perlakuan apapun hanya menggunakan media gambar.

Selanjutnya, kelompok yang diberikan perlakuan diberi nama kelompok Eksperimen, dan kelompok yang tidak diberi perlakuan diberi nama Kelompok
Kontrol. Rancangan Penelitiannya dapat dilihat dibawah ini :

\begin{tabular}{|ccc|}
\hline $\mathbf{R}$ & $\mathbf{X}$ & $O_{1}$ \\
$\mathbf{R}$ & & $O_{2}$ \\
\hline
\end{tabular}

Keterangan :

$\mathrm{R}=$ Random Kelompok

$\mathrm{X}$ = Perlakuan

$O_{1}=$ Post Test kelompok

Eksperimen

$\mathrm{O}_{2}=$ Post test kelompok Kontrol

Perlakuan dalam penelitian ini yaitu pembelajaran menggunakan media Jendela Ilmu.

Selanjutnya, peneliti menentukan populasi dan sampel yang digunakan di dalam penelitian. Populasi yang digunakan adalah siswa kelas V SDN Tenggilis Mejoyo 1 Surabaya. Pemilihan sampel dalam penelitian adalah Non Random sampling yaitu Purposive sampling atau sampel bertujuan. Sampel yang digunakan adalah siswa kelas VA yang dijadikan kelas Eksperimen dan VB yang dijadikan kelas Kontrol. Pada saat penelitian, kelas Eksperimen akan menggunakan media pembelajaran Jendela Ilmu, sementara kelas Kontrol akan menggunakan media gambar.

Data Hasil Penelitian didapatkan dari metode tes yang digunakan untuk mengetahui ada atau tidaknya pengaruh penggunaan media pembelajaran Jendela ilmu terhadap hasil belajar IPS Siswa kelas V SDN Tenggilis Mejoyo 1 Surabaya. Metode tes dilakukan setelah pelajaran berlangsung. Tes dilakukan secara individu untuk mengetahui apakah siswa sudah memahami materi yang diajarkan. 
Tes akan dilakukan pada Kelas kontrol dan pada kelas eksperimen.

Evaluasi/tes dibuat dalam bentuk uraian yang berjumlah 5 soal dan obyektif yang berjumlah 10 soal. Dimana pengerjaan tes ini diberi waktu antara 15-20 menit sesuai dengan materi yang sudah diberikan pada pembelajaran IPS yaitu tentang Tokoh - Tokoh Sejarah Pada Masa Kerajaan Hindhu - Budha dan Islam di Indonesia. Yang mencakup beberapa sub pokok bahasan yaitu :

a. Tokoh-Tokoh Sejarah Kerajaan Kutai

b. Tokoh-Tokoh Sejarah Kerajaan Tarumanegara

c. Riwayat Raja Kerajaan Kutai

d. Riwayat Raja Kerajaan Tarumanegara

Selanjutnya dilakukan uji Homogenitas sebelum menganalisis data penelitian yang diperoleh, uji Homogenitas menggunakan nilai Ulangan Tengah Semester IPS yang telah dilakukan oleh kelas VA dan VB. Setelah dilakukan Uji Homogenitas barulah data yang diperoleh dari hasil Tes Hasil Belajar dianalisis menggunakan uji-t, yang dapat ditentukan dengan langkah sebagai berikut:

1. Menentukan hipotesis yang akan di uji.

Ho : Tidak ada pengaruh penggunaan media pembelajaran 'Jendela ilmu' terhadap hasil belajar siswa. $(\mathrm{Ho}=0)$
Ha : Ada pengaruh penggunaan media pembelajaran 'Jendela Ilmu' pada hasil belajar siswa $(\mathrm{Ha} \neq 0)$

2. Menentukan taraf signifikansi : $5 \%$
3. Menghitung besarnya thitung

4. Menentukan daerah penolakan Ho ditolak jika thitung $>$ ttabel

5. Menarik kesimpulan

\section{HASIL PENELITIAN}

Setelah dianalisis maka diketahui bahwa kedua kelas yang digunakan sebagai subjek penelitian bersifat Homogen, yang artinya kemampuan yang dimiliki oleh kedua kelas tersebut kurang lebih sama.

Selanjutnya dilakukan uji normalitas data hasil Tes Hasil Belajar yang sudah diperloeh, untuk membuktikan bahwa data yang dianalisis bersifat normal. Uji normalitas menggunakan rumus COV (Coefficient of Variant).

Setelah itu, Analisis Uji-t dilakukan, dan diperoleh $\mathrm{t}$ hitung sebesar 2,64. Yang kemudian direlasikan dengan tabel nilai $\mathrm{t}$ untuk dk = (n1 + n2 - 2), $(34+34-$ 2) $=66$. Dalam taraf signifikansi $5 \%$ diperoleh nilai t tabel yaitu 1,996, yang berarti thitung $>$ tabel. Hal tersebut berarti $\mathrm{H}_{\mathrm{o}}$ ditolak sementara Ha diterima, yang artinya adalah, media pembelajaran Jendela Ilmu mempengaruhi Hasil Belajar IPS Siswa Kelas V SDN Tenggilis Mejoyo 1 Surabaya.

\section{PEMBAHASAN}

Hasil penelitian yang dilakukan penulis di SDN Tenggilis Mejoyo 1 Surabaya, Tahun Pelajaran 2012/2013, dengan media pembelajaran Jendela ilmu dalam proses pengajaran Ilmu Pengetahuan Sosial pada Materi Tokoh-Tokoh Kerajaan Hindhu-Budha dan Islam di Indonesia, memberikan hasil belajar yang memuaskan dibandingkan 
hanya dengan menggunakan media gambar. Hal ini dibuktikan dari hasil pengolahan uji-t dengan tujuan untuk mengetahui pengaruh media pembelajaran Jendela ilmu terhadap hasil belajar siswa kelas V SDN Tenggilis Mejoyo 1 Surabaya.

Hasil analisis menunjukkan bahwa nilai thitung lebih besar daripada nilai tabel pada taraf signifikan 5\% (thitung $>$ ttabel), yaitu thitung adalah 2,64. Dengan hasil tersebut maka dapat dinyatakan bahwa penggunaan media pembelajaran Jendela Ilmu berpengaruh terhadap hasil belajar Ilmu Pengetahuan Sosial (IPS) siswa kelas V SDN Tenggilis Mejoyo 1 Surabaya.

Hasil Penelitian juga tidak terlepas pada asumsi dasar yang digunakan oleh penulis, yang sekaligus menjadi alasan mengapa penggunaan media pembelajaran Jendela Ilmu perlu diterapkan pada Pembelajaran Ilmu Pengetahuan Sosial. Dalam proses pembelajaran tidak terlepas dari pengembangan aspek kognitif, afektif dan psikomotor siswa.

Dengan menggunakan media pembelajaran Jendela Ilmu, memungkinkan siswa untuk mengingat sebuah pengetahuan dengan cara yang menyenangkan, yaitu dengan cara bermain. Selain itu, media ini dapat melatih afektif siswa, misalnya saja, rasa ingin tahu, cermat dalam membaca suatu soal, cekatan, Jujur dan bertanggung jawab atas apa yang sudah dilakukannya serta kerjasama dalam kelompok. Media Jendela Ilmu juga dapat melatih psikomotor siswa, dimana siswa akan aktif bergerak di dalamnya, karena siswa yang mengatur jalannya permainan, sementara guru atau pengajar hanya mengawasi dan membimbing saja.

\section{SIMPULAN DAN SARAN}

Berdasarkan hasil analisis data disimpulkan bahwa media pembelajaran Jendela Ilmu membawa pengaruh yang signifikan dalam pembelajaran Ilmu Pengetahuan Sosial (IPS) di SDN Tenggilis Mejoyo 1 nomor 262 Surabaya Tahun Pelajaran 2012/2013. Hal ini dibuktikan dengan hasil uji-t, diperoleh thitung sebesar 2,64. Yang kemudian direlasikan dengan tabel nilai $\mathrm{t}$ untuk $\mathrm{dk}=(\mathrm{n} 1+\mathrm{n} 2-2),(34+34-$ 2) $=66$. Dalam taraf signifikansi $5 \%$ diperoleh nilai $\mathrm{t}$ tabel yaitu 1,996, yang berarti thitung $>$ tabel. Hal tersebut berarti $\mathrm{H}_{\mathrm{o}}$ ditolak sementara Ha diterima, sehingga dapat ditarik kesimpulan sebagai berikut.

$\begin{array}{cr}\text { Penggunaan } & \text { media } \\ \text { pembelajaran Jendela Ilmu }\end{array}$ mempengaruhi hasil belajar siswa kelas V dalam pembelajaran Ilmu Pengetahuan Sosial (IPS) di SDN Tenggilis Mejoyo 1 nomor 262 Surabaya Tahun Pelajaran $2012 / 2013$. Hal ini terbukti dari rata-rata hasil belajar eksperimen 83,82, lebih besar dari rata-rata hasil belajar kelompok kontrol sebesar 75,23. Dengan hasil ketuntasan belajar siswa, dimana pada kelas Eksperimen yang menggunakan media Jendela Ilmu, 27 siswa Tuntas, dan hanya 5 siswa tidak tuntas. Sementara untuk kelas Kontrol, dari 34 siswa sebanyak 24 siswa tuntas dan 10 siswa tidak tuntas.

Atas dasar hasil penelitian dan kesimpulan tersebut di atas, maka dengan tujuan meningkatkan 
mutu pengajaran dan hasil belajar Ilmu Pengetahuan Soaial (IPS), maka penulis memberikan saran sebagai berikut :

1. Media Pembelajaran Jendela Ilmu perlu disosialisasikan, karena dapat menjadi alternatif atau inovasi media di dalam suatu pembelajaran, terutama dalam pembelajaran Ilmu Pengetahuan Sosial (IPS).

2. Media Pembelajaran Jendela ilmu perlu diteruskan dan dikembangkan pada materi lainnya agar siswa dengan mudah memahami materi yang diajarkan oleh guru.

\section{DAFTAR PUSTAKA}

Anitah, Sri. 2008. Media Pembelajaran. Surakarta : UNS Press

Arikunto, Suharsimi., Suhardjono., Supardi. 2012. Penelitian Tindakan Kelas. Jakarta : Bumi Aksara

Gintings, Abdorrakhman. 2008. Esensi Praktis Belajar dan Pembelajaran. Bandung : Humaniora

Isjoni, H. 2007. Cooperative Learning efektifitas pembelajaran kelompok. Bandung : Alfabeta

Menteri Pendidikan Nasional republik Indonesia. 2007. Peraturan Menteri Pendidikan Nasional republik Indonesia. Jakarta : BP. Cipta Jaya

Musfiqon, M. 2012. Metodologi Penelitian pendidikan. Jakarta : Prestasi Pustaka

Nasution, Noehi., Suryanto, Adi. 2008. Evaluasi Pengajaran. Jakarta : Universitas Terbuka

Roestiyah. 2008. Strategi Belajar Mengajar. Jakarta : Rineka Cipta
Rusman. 2012. Model - Model Pembelajaran

Mengembangkan

Profesionalisme Guru Edisi Kedua.Jakarta : Grafindo

Sanjaya, Wina. 2008. Perencanaan dan Desain Sistem Penelitian. Jakarta : Kencana

Santoso, Gempur. 2007. Metodologi Penelitian kuantitatif dan kualitatif. Jakarta : Prestasi pustaka

Sudjana, Nana. 1989. Penilaian Hasil Proses Belajar Mengajar. Bandung : PT. Remaja Rosdakarya

Sudjana. 2005. Metoda Statistika. Bandung : Tarsito

Sugiyono. 2011. Metode Penelitian Kuantitatif dan Kualitatif dan $R \& D$. Bandung : Alfabeta

Sugiyono. 2012. Statistika untuk penelitian. Bandung : Alfabeta

Sunardi, Hartanto. Pramesti. 2007. Statistika. Surabaya : Universitas PGRI Adi Buana Surabaya.

Suwandi, Sarwiji. 2011. Model-Model Asesmen Pendidikan. Surakarta : Yuma Pustaka

Supartini. 2011. Pengaruh model TGT terhadap hasil pembelajaran. Universitas PGRI http://carapedia.com/model_pembel ajaran_stad_info599.html diakses tanggal 1 Februari 2018 pukul 11.29

http://goeroendeso.wordpress.com/ 2009/02/07/peranan-media-pembel ajaran/diakses tanggal 01 Februari 2018 pukul 13.57

http://hendriansdiamond.blogspot.c om/2012/01/pengertian-faktor-dan indikator-hasil.html diakses tanggal 1 Februari 2018 pukul 15.03 
http://id.shvoong.com/social-science s/education/2196975-indikator-indi kator-keberhasilan-pembelajaran/ diakses tanggal 1 Februari 2018 pukul 15.04

http://saefullohlipana.blogspot.com/ 2012/05/pengumpulan-data.html diakses tanggal 01 Februari 2018 pukul 13.57

http://tepenr06.wordpress.com/201 1/10/30/teknik-pengumpulan-data/ diakses tanggal 01 Februari 2018 pukul 10.00

http://vildahzakkiyah.blogspot.com/ 2012/04/pengertian-kerucut-pengal aman-edgar.html diakses tanggal 10 Februari 2018 pukul 11.30

http://www.farhan-bjm.web.id/2011 109/model-pembelajaran-kooperatiftipe-stad.html diakses tanggal 10 Februari 2018 pukul 11.30. 